\title{
Improving the Power Quality in Tehran Metro Line-Two Using the Ant Colony Algorithm
}

\author{
Hossein Ehteshami \\ Electrical Engineering Dpt \\ Kashan Branch, Islamic Azad \\ University \\ Kashan, Iran
}

\author{
Saeid Javadi \\ Electrical Engineering Dpt \\ Amirkabir University of Technology \\ Tehran, Iran
}

\author{
Seyed Mohammad Shariatmadar \\ Electrical Engineering Dpt \\ Naragh Branch, Islamic Azad \\ University \\ Naragh, Iran
}

\begin{abstract}
This research aims to survey the improvement of power quality in Tehran metro line 2 using the ant colony algorithm and to investigate all the factors affecting the achievement of this goal. In order to put Tehran on the road of sustainable development, finding a solution for dealing with air pollution is essential. The use of public transportation, especially metro, is one of the ways to achieve this goal. Since the highest share of pollutants in Tehran belongs to cars and mobile sources, relative statistical indicators are estimated through assuming the effect of metro lines development and subsequently reduction of traffic on power quality index.
\end{abstract}

Keywords-power; quality; improvement; Tehran; metro; ant colony; algorithm; index

\section{INTRODUCTION}

In the last two decades, a remarkable growth in rail transport systems has occurred. The world's fastest passenger rail vehicles are made in France and Japan [1]. New rail lines in transport and fleet are important in terms of dynamic interaction. The type and quality of rail lines play a significant role in this field. Rail lines range in various groups of power. Trains' power of movement is a decisive parameter from the aspect of mobility comfort, resisting forces and dynamic interaction of wheel and rail. In addition, it should be mentioned that any range of power requires its own control system necessities [2]. Since the first passenger trains [3], heavy rail transit systems usually refer to the underground and elevated rails. In these lines, high capacity electric trains move on routes separated from other transport systems. Subway stations have great length and height and electric energy consumption is usually supplied through the third rail. Suburban transport system areas are constructed between urban rail transportation systems and residential and commercial centers hence they are also called Metro Links [4]. In suburban lines, the distance between stations is high ( 3 to 6 miles); therefore, the power of movement is larger than that of the urban rail systems (about $80 \mathrm{~km} / \mathrm{hr}$ ). The suburban trains are usually scheduled for peak commute hours. Usually any rail transportation system using only one independent rail is called monorail. Commonly the rails are in a height, but there are intersections or underpasses. The wagons can be hanged from the rails or move on them. In terms of movement and control, monorail system is in the category of Automated Guide way Transit (AGT) [5]. Tehran Metro line 2 is a completely urban line with $26 \mathrm{~km}$ length and 22 stations, 8 of which are also connected to other lines. With the operation of line 2, the move time from East of Tehran to the West decrease to 40 minutes.

\section{IMPROVEMENT OF POWER QUALITY}

Power quality is one of the most important issues of electric loads. Any noise in voltage, frequency and current losses can damage electrical equipment [6]. Retail markets must set the natural transmission of electricity (transmission and distribution) and other services contracted with the consumers in order to supply their demand. The subject is the improvement of power quality indexes, better voltage regulation and modification of power factor from the advantages of DGs usage which is not possible in central systems of production. There isn't any voltage adjustment in the power systems because of the enhancement of the transmission power. There are also other parameters such as economic and biological problems which influence the structure of power network. There are many factors which affect the inclination of using smart networks. These factors are: reduction of lines losses, enhancement of voltage profile, reduction of the issuance of emissions, development of network security, enhancement of power quality, development of efficiency, increase of security of the sensitive loads and enhancement of the capacity of transmission and distribution system [7]. One of the most important problems is supplying the quality which is accepted by the consumers [8]. Frequently, the following issues are presented about the electronic quality discussion:

- Gradual development of general output.

- The possibility of distortion

- Misfunction of electronic devices.

\section{ANALYSIS METHOD}

First, we should review the power equations to analyze the power quality in the train. 


$$
\begin{aligned}
& P_{M}=\frac{1}{2} \rho_{A i r} V^{3} \pi R^{2} C_{P}(\lambda, \beta) \\
& P_{M}=\omega_{M} T_{M} \\
& C_{P}=\frac{P_{M}}{P_{V}} \\
& \lambda=\frac{\omega_{M} R}{V}
\end{aligned}
$$

where $\mathrm{P}_{\mathrm{m}}$ is the mechanical power of the train, $\mathrm{P}_{\text {air }}$ is the air density, $\mathrm{V}$ is the wind power, $\omega_{\mathrm{m}}$ is the power of rotation, $\beta$ is the blade angle, $\mathrm{T}_{\mathrm{M}}$ is the mechanical torque, and $\mathrm{R}$ is the radius of the turbine. Curve Power $(\mathrm{CP})$ for a given peak power and also $\lambda=\frac{\omega_{M} R}{V}$ are given by manufacturer. Note that $\mathrm{CP}$ should not exceed the upper limit theory [9]. $C_{P}^{M A X}=16 / 27 \cong 0.59$

\section{THE ANT COLONY ALGORITHM}

An assembly of ants, bees and/or all kind of social insects is a distributed system that despite the simplicity of each of them creates a highly structured social organization. The ant colony can perform complex tasks which are beyond the capabilities of individual ants [10]. The subject of "ant colony" reviews the derived samples of the actual behavior of ants and uses these samples as a source of inspiration for the design of new algorithms [11]. The algorithm was suggested for solving the vendor issue with 75 cities in 1991 and was called ant system which was the prototype Ant Colony Algorithm. This algorithm had three features:

- Versatility: same issues could be solved with the algorithm such as using the vendor symmetric algorithm for solving vendor asymmetric issues.

- Capabilities: with modifying algorithm, other problems can be solved in Hybrid Optimization. The algorithm is not affected by parametric changes.

- Population-based: allows the algorithm to have a positive feedback mechanism for finding correct answer rapidly. It also allows parallel execution. In addition, it will prevent convergence and get caught in the initial optimal solution due to the decentralized computing.

The process of the algorithm is the following:

- Determine the initial value for pheromone function and innovative function

- Insert the city of origin on the blacklist for each ant

- Calculate the probability function to select the next town for each ant in each city

- Modify urban populations for each course

- Adding the selected city to blacklist for each ant

- Determine the best route
- Update

\section{FUNCTIONS AND ELEMENTS OF ANT COLONY ALGORITHM}

A. The Function of Pheromones

$$
\begin{aligned}
& \Delta \tau_{i j}^{k}(\mathrm{t}, \mathrm{t}+1)=Q / d_{i j} \\
& \Delta \tau_{i j}(t, t+1)=\sum_{k-1}^{m} \Delta \tau_{i j}^{k}(t, t+1)
\end{aligned}
$$

In the first equation, the pheromones amount of $\mathrm{k}$-th ant is calculated on $\mathrm{d}_{\mathrm{ij}}$ and in second equation the total pheromone is calculated on the edge with the passage of $\mathrm{m}$ ants.

\section{B. Routing Algorithm Based on Ant Colony}

This algorithm shows the details of routing scheme for MANETS which includes route discovery and support mechanisms. The route discovery will be completed by reaching the pioneer ant and reversing links to the destination. This mechanism looks like the AODV algorithm. Routes primarily are kept by data packets. This means that if a path fails, it temporarily creates a package and sends it to alternate links. Otherwise, it returns to the previous hop for simulation. If the package eventually returns to the origin, finding the new direction has been created sequentially.

\section{Ant Routing Algorithm}

Each node in the grid keeps a record of destination package which passes through the node. According to the information in the table, the first movement of pioneer ant makes a decision for next hop which wants to take the node. The pioneer ant collects all information about the nodes and time. In future, this information will be updated. The next move to reach the neighbor node is calculated by a simple formula:

$$
\mathrm{D}_{i j}+\left(\mathrm{q}_{\mathrm{ij}}+\mathrm{s}_{\mathrm{a}}\right) / B_{i j}
$$

For reaching the destination, the score of the trip is calculated and the pioneer ant becomes a secondary ant. The secondary ant comes back through the captured path and uses the queue of the data packet. The secondary ant uses priority queues. The simulation can be summarized as: The topology shows the origin and then calculates the time delay. After confirming the ant algorithm on the current topology, the likelihood will be applied on routing tables, and it will recalculate the delay [12]. If the new delay was better, it will change the origin node for pioneer ant. Then it accepts the new solution. The comparison between the delays indicates the best one. When $\mathrm{T}_{\text {ant }}$ is over but $\mathrm{T}_{\text {simul }}$ is not over yet, the new topology of the grid will be simulated based on mobile models of RWM and BSAM till the $\mathrm{T}_{\text {simul }}$ gets over.

\section{PROBLEM OPTIMIZATION BY ANT COLONY}

Ant colony optimization algorithm is highly efficient in combinatorial optimization problems [13]. The ant algorithm is a good example of collective intelligence where agents with low capabilities work together and create very good results. This algorithm is useful to solve optimization problems, for 
example the train movement behavior for the distance between two stations. In current case we study the power profile of a train movement for a route of Tehran subway line 2 . Initially we need route information like:

- The start point of train movement in first station: $\mathrm{x}_{\min }=200 \mathrm{~m}$

- The endpoint of the route in second station: $\mathrm{x}_{\max }=1450 \mathrm{~m}$

With respect to the information we have, line slope of the start and end of the route is 0 and in the distance between start and end the slope is 0.03 percent.

- The point that the slope changes after train starts movement: $\mathrm{x}_{1}=430 \mathrm{~m}$

- The point that the slope becomes 0 before the train reaches to final station: $x_{2}=1315 \mathrm{~m}$

With respect to the route information mentioned above, the train has 0 slope from the movement start point in $x_{\min }=200 \mathrm{~m}$ to the first point that slope changes in $\mathrm{x}_{1}=430 \mathrm{~m}$, and from this point to the distance of $\mathrm{x}_{2}=1315 \mathrm{~m}$ the slope is $0.03 \%$. From this point to the end of the route the slope is again 0 (slope 0 means that the train continues movement in a horizontal path). Horizontal paths that are at the start and end of the route show the points in which the train reaches to passengers platforms. The other information that we need to study the train power profile is the limitation of train movement power.

- Power limitation from the start point to the point $\mathrm{x}=505 \mathrm{~m}$ is equal to: $\mathrm{v}=65 \mathrm{~km} / \mathrm{h}$

- Power limitation from the point $\mathrm{x}=505 \mathrm{~m}$ to the point $\mathrm{x}=705 \mathrm{~m}$ is equal to: $\mathrm{v}=50 \mathrm{~km} / \mathrm{h}$

- Power limitation from the point $\mathrm{x}=705 \mathrm{~m}$ to the end of the path $x_{\max }=1450 \mathrm{~m}$ is equal to: $v=65 \mathrm{~km} / \mathrm{h}$

The optimal time the train passes the distance between these two stations is equal to 110 seconds. The first repetition of the algorithm is shown in Figure 2. Point $\mathrm{p}_{1}$ shows the start moment of train movement with power 0 . Point $\mathrm{p}_{2}$ shows the point of the path slope change. The train power decreases after reaching this point because it enters a steep path. Point $\mathrm{p}_{3}$ is the path strategic point in which the train changes from acceleration state to neutral state. Point $\mathrm{p}_{4}$ is where the train experiences the slope change again. In $\mathrm{p}_{5}$ the train brakes while entering the station to stop in $\mathrm{p}_{6}$ which shows the platform. The blue diagram is related to the train movement and the yellow diagram shows power limitation. It is obvious that in the first repetition using imperialist competitive algorithm, the power limitation is not observed and the train power exceeds the allowed power, therefore we need the other operations of this program to observe the power range. With the second repetition the results in Figure 2 are obtained for train power profile. In Figure 2 the profile of the train movement power is decreased and along the total cost is decreased, but again the power limitation condition is not observed in second repetition, therefore the program enters its third repetition. Using the following relationship, energy consumption for train movement is obtained: Total energy consumption= time of acceleration / required electrical power for acceleration.

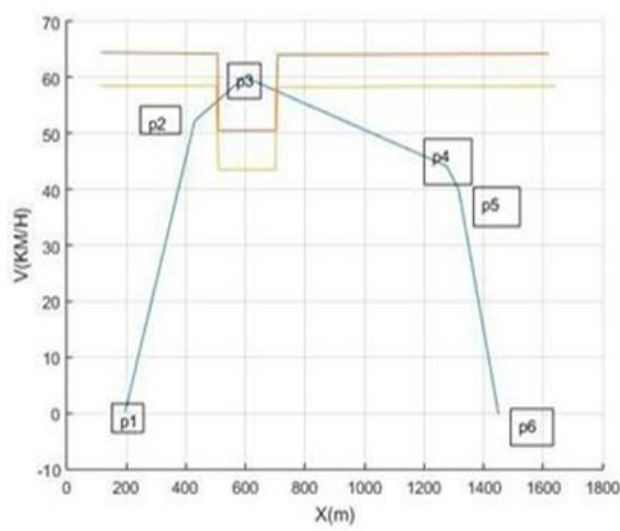

Fig. 1. Power profile for determined path with the first repetition with one variable.

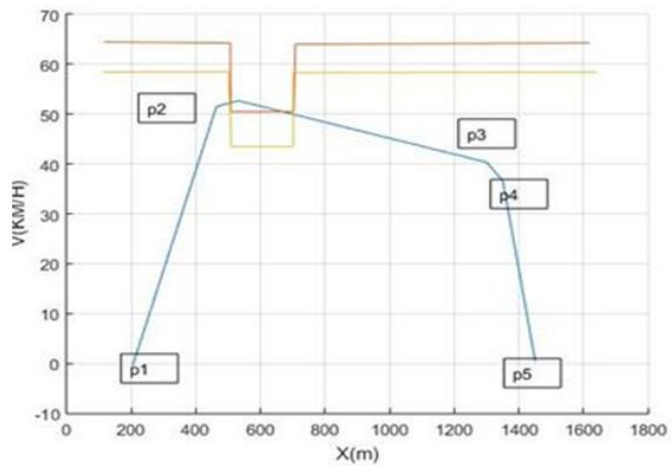

Fig. 2. Power profile after applying second repetition with one variable.

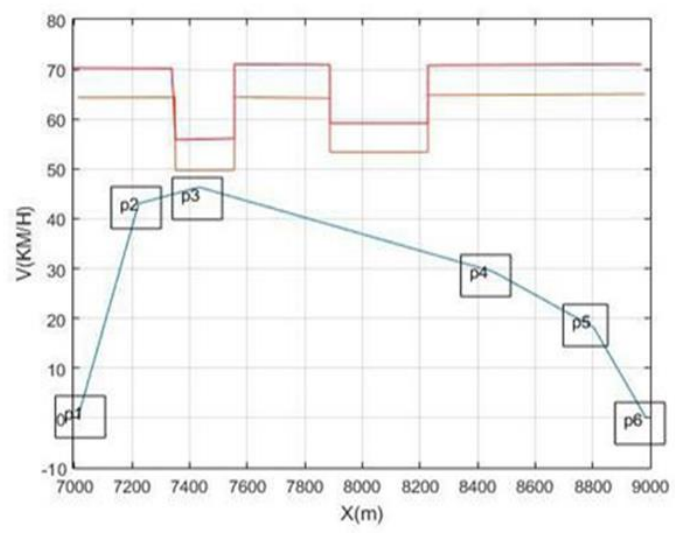

Fig. 3. Power profile for the third acclivity path with one variable

\section{CONCLUSION}

In order to find an optimal power profile we have to look for points of modifying strategy. This means to determine numbers in allowed range for strategy change variables that optimize the power profile. Numerous points could be 
effective. In other words, we study each path using different numbers of variables and finally we choose the highest response. We used the ant colony algorithm to compare the gathering results. In fact, we changed the train problem into a mathematical problem: to find a minimum point in ' $n$ ' dimensions environment for an anonymous function. By generating random numbers and combining them, the ant colony algorithm method tries to find the optimal point to create new numbers.

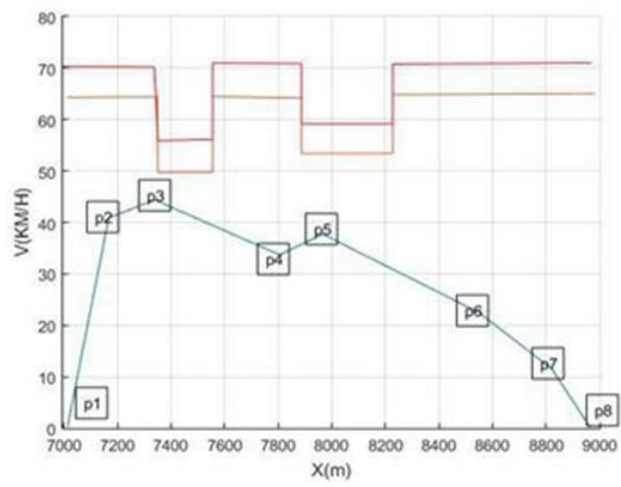

Fig. 4. Power profile for the third acclivity path with three variables.

\section{REFERENCES}

[1] S. Shiee, M. Omidi, "Planning land use around stations of Tehran subway line2 with emphasis on transit- oriented development", National Conference on Architecture, new urban development, Vol. 1, No. 2, pp. $10-15,2015$

[2] M. Montazeri, B. Rahnavard, "Supporting domestic manufacturers of subway industry equipments using strategic alliance model", $15^{\text {th }}$ International Conference on traffic and transportation engineering, Vol. 1 , pp. 5-7, 2014
[3] M. Niksirat, M. Ghatee, S. Mehdi Hashemi, "Multimodal K-shortest viable path problem in Tehran public transportation network and its solution applying ant colony and simulated annealing algorithms", Applied Mathematical Modelling, Vol. 36, No. 11, pp. 5709-5726, 2012

[4] H. Seifi, M. S. Sepasian, Electric power system planning: issues, algorithms and solutions, Springer Science \& Business Media, 2011

[5] M. H. Almasi, A. Sadollah, S. Kang, M. R. Karim, "Optimization of an Improved Intermodal Transit Model Equipped with Feeder Bus and Railway Systems Using Metaheuristics Approaches", Sustainability, Vol. 8, No. 6, pp. 537-563, 2016

[6] R. Dehini, S. Sefiane, "Power quality and cost improvement by passive power filters synthesis using ant colony algorithm", Journal of Theoretical and Applied Information Technology, Vol. 23, No. 2, pp. 70-79, 2011

[7] R. S. Parpinelli, H. S. Lopes, A. A. Freitas, "Data mining with an ant colony optimization algorithm", IEEE Transactions on evolutionary computation, Vol. 6, No. 4, pp. 321-332, 2015

[8] Y. H. Song, C. S. Chou, T. J. Stonham, "Combined heat and power economic dispatch by improved ant colony search algorithm", Electric Power Systems Research, Vol. 52, No. 2, pp. 115-121, 2014.

[9] R. S. Parpinelli, H. S. Lopes, A. A. Freitas, "An ant colony algorithm for classification rule discovery" in: Data mining: A heuristic approach, pp. 191-208, Idea Group Publishing, 2012

[10] D. Niu, Y. Wang, D. D. Wu, "Power load forecasting using support vector machine and ant colony optimization", Expert Systems with Applications, Vol. 37, No. 3, pp. 2531-2539, 2010

[11] M. Dorigo, G. Di Caro, L. M. Gambardella, "Ant algorithms for discrete optimization", Artificial life, Vol. 5, pp. 137-172, 1999

[12] L. Slimani, T. Bouktir, "Economic power dispatch of power systems with pollution control using artificial bee colony optimization", Turkish Journal of Electrical Engineering \& Computer Sciences, Vol. 21, No. 6, pp. 1515-1527, 2014

[13] B. Yu, Z. Z. Yang, B. Yao, "An improved ant colony optimization for vehicle routing problem", European Journal of Operational Research, Vol. 196, No. 1, pp. 171-176, 2015 